\title{
Size distributions of elemental carbon and its contribution to light extinction in urban and rural locations in the pearl river delta region, China
}

\author{
H. $\mathbf{Y u}^{1,2}$, C. $\mathbf{W u}^{1,3}$, D. $\mathbf{W u}^{4}$, and J. Z. Yu $\mathbf{u}^{1,2}$ \\ ${ }^{1}$ Division of Environment, Hong Kong University of Science and Technology, Clear Water Bay, Kowloon, Hong Kong, China \\ ${ }^{2}$ Department of Chemistry, Hong Kong University of Science and Technology, Clear Water Bay, Kowloon, Hong Kong, China \\ ${ }^{3}$ Atmospheric Research Center, HKUST Fok Ying Tung Graduate School, Nansha, Guangzhou 511458, China \\ ${ }^{4}$ Institute of Tropical and Marine Meteorology, China Meteorological Administration, Guangzhou 510080, China
}

Received: 21 August 2009 - Published in Atmos. Chem. Phys. Discuss.: 30 October 2009

Revised: 17 May 2010 - Accepted: 28 May 2010 - Published: 8 June 2010

\begin{abstract}
Elemental carbon (EC) in size-segregated aerosol samples were determined at five urban, one suburban, and one rural locations in the Pearl River Delta region in South China during 2006-2008 period. The size modal characteristics of EC were different at the urban and suburban/rural locations. The urban EC had a dominant condensation mode with a mass median aerodynamic diameter (MMAD) in the $0.36-0.43 \mu \mathrm{m}$ range and a slightly less abundant mode in the droplet mode size (MMAD: 0.8-1.1 $\mu \mathrm{m}$ ), while the suburban/rural EC had a prominent mode in the droplet mode size (MMAD: $0.7-1.1 \mu \mathrm{m}$ ) and a minor condensation mode (MMAD: $0.22-0.33 \mu \mathrm{m}$ ). Calculations using Mie theory and the measured size distributions of EC, organic carbon, and major inorganic ions indicate that EC-containing particles contributed $76 \pm 20 \%$ of the observed light extinction at the urban sites. Among the EC-containing particles, EC mass alone contributed $21 \pm 11 \%$ of the observed light extinction while non-EC materials on the EC particles (i.e., organic matter, ammonium sulfate, and water) contributed $55 \pm 15 \%$. At the suburban/rural locations, EC-containing particles contributed $37-48 \%$ of the measured light extinction, with EC mass contributing 4-10\% and non-EC coating materials contributing the remaining light extinction. Our results suggest that EC-containing particles were important to the overall light extinction in the urban atmospheres due to their more abundant presence from vehicular emissions. The ECcontaining particles in the suburban/rural locations had a reduced but still significant contribution to light extinction budget.
\end{abstract}

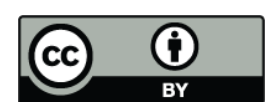

Correspondence to: J. Z. Yu (chjianyu@ust.hk)

\section{Introduction}

Element carbon (EC) and organic carbon (OC) make up a significant fraction of ambient aerosol mass. The Pearl River Delta (PRD) region is a fast-developing economic zone located on the southeast coast of China. Abundance of EC and OC in bulk $\mathrm{PM}_{2.5}$ or $\mathrm{PM}_{10}$ aerosol samples in the PRD region have been reported in a number of studies (Ho et al., 2002, 2006; Cao et al., 2003, 2004; Yu et al., 2004; Chow et al., 2005; Duan et al., 2007; Hagler et al., 2006; Andreae et al., 2008). The concentrations of $\mathrm{EC}$ in $\mathrm{PM}_{10}$ were $4.7-10.4 \mu \mathrm{g}$ $\mathrm{m}^{-3}$ in urban locations and $2.5-6.2 \mu \mathrm{g} \mathrm{m}^{-3}$ in suburban locations. The cumulative evidence presented in these studies indicates that EC in the PRD region came mainly from vehicle emissions.

The worsening visibility degradation is of increasing public concern in the PRD region (e.g., Wu et al., 2007). The attenuation of light has contributions from EC, OC, and other aerosol constituents such as sulfate, sea salt, nitrate, and crustal materials as well as gas molecules (Lai and Sequeira, 2001; Malm et al., 1994; Bergin et al., 2001; Hasan and Dzubay, 1983). EC is the primary light absorption constituent in ambient aerosols (Horvath, 1993; Jacobson, 2001). Andreae et al. (2008) obtained a mass absorption efficiency (MAE) of EC of $7.7 \mathrm{~m}^{2} \mathrm{~g}^{-1}$ in urban Guangzhou by regressing the measured absorption coefficient against EC and OC. Wang (2003) used a modified IMPROVE formula and estimated that EC and OC contributed $12 \%$ and $17 \%$ of light extinction in a rural location and $26 \%$ and $21 \%$ in an urban area in Hong Kong. Using Mie theory and assuming that all components were externally mixed, Cheng et al. (2008) calculated the fractional contributions of EC and OC to light

Published by Copernicus Publications on behalf of the European Geosciences Union. 
extinction to be at the same value of $17 \%$ in Xinken, a rural location in the PRD region.

Knowledge of EC size distribution is essential in studying aerosol light extinction (Horvath, 1995; Vanderlei Martins et al., 1998; Sloane et al., 1991). EC size distribution measurements in the PRD region are limited. Gnauk et al. (2008) measured EC, OC, and a few selected organic compound classes in size-segregated aerosols in Xinken, a rural/coastal background site $60 \mathrm{~km}$ to the southeast of Guangzhou. Our group reported EC size distributions in Shenzhen and Guangzhou, two metropolitan cities in the $\mathrm{PRD}$ region (Huang and $\mathrm{Yu}, 2008$; $\mathrm{Yu}$ and $\mathrm{Yu}, 2009$ ). In this study, we report the measurements of EC size distributions at five urban locations in Guangzhou throughout a one-year period from December 2006 to December 2007 and one suburban and one rural location in the PRD region in selected summer and winter months. Light extinction due to aerosols can be calculated theoretically for spherical particles of known size and composition (van de Hulst, 1981; Bohren and Huffman, 1983). The objective of this study was to evaluate the contribution of EC-containing particles to light extinction at selected urban and suburban/rural locations in the PRD region.

\section{Experimental section}

\subsection{Aerosol sample collection and chemical analysis}

Size-segregated aerosol samples were collected at five urban, one suburban, and one rural site in the PRD region and their locations are shown in Fig. 1a. The five urban sites are meteorological monitoring stations set up by the Guangzhou (GZ) local meteorology administration and they are within a radius of $7.5 \mathrm{~km}$ in the GZ urban area $\left(23^{\circ} 18^{\prime} 03^{\prime \prime} \mathrm{N}, 113^{\circ} 15^{\prime} 50^{\prime \prime} \mathrm{E}\right)$. GZ has 27 million inhabitants and 1.83 million vehicles (Guangzhou Transport Planning Research Institute, 2006). The rural site is Backgarden (BG) $\left(23^{\circ} 29^{\prime} 14^{\prime \prime} \mathrm{N}, 113^{\circ} 02^{\prime} 18^{\prime \prime} \mathrm{E}\right)$, located $50 \mathrm{~km}$ to the northwest of GZ. The suburban site is on the campus of Hong Kong University of Science and Technology (HKUST, $23^{\circ} 19^{\prime} 12^{\prime \prime} \mathrm{N}, 114^{\circ} 16^{\prime} 12^{\prime \prime} \mathrm{E}$ ), a suburban location on the southeast coast of Hong Kong. There are no local industries or intensive vehicular traffic at the rural and the suburban locations.

In summer, the prevailing southeast monsoon places the BG site downwind of the GZ urban area while the HKUST site is upwind of the PRD region. In winter, the northwest monsoon affects the region and places HKUST in downwind of the PRD region. The upwind and downwind relationships among the three sites are demonstrated in two wind vector maps of the PRD region generated by MM5 model based on local surface wind observations (Fig. 1b and c) (Fung et al., 2005).
Table 1 lists the sampling details at each location. A total of 29 sets of size-segregated aerosol samples were collected at the five urban sites using eight-stage cascade impactor samplers (Thermo Andersen, Waltham, MA, USA) in the months of January, April, May, July, October, November and December in 2006-2007. The sampling season covered winter, spring, summer and fall in GZ. Sample collection at the BG and HKUST sites was carried out using a tenstage Micro-Orifice Uniform Deposit Impactor (MOUDI, MSP Corp, Shoreview, MN USA). Seven sets of samples were collected at BG in July 2006. At HKUST, eight sets of samples were collected in August 2007 and ten sets were collected in January and February 2008. The sample duration ranged from one to three days. Quartz fiber filters were used as collection substrate in all the samples. Field blank samples were collected in each sampling period.

Filters were stored at $4{ }^{\circ} \mathrm{C}$ until EC and OC were analyzed using a thermal/optical transmittance aerosol carbon analyzer (Sunset Laboratory, OR) (Birch and Cary, 1996). The first stage of analysis, during which helium is the carrier gas, consisted of four temperature steps at $310^{\circ} \mathrm{C}\left(\mathrm{OC}_{1}\right)$, $475^{\circ} \mathrm{C}\left(\mathrm{OC}_{2}\right), 615^{\circ} \mathrm{C}\left(\mathrm{OC}_{3}\right)$, and $870^{\circ} \mathrm{C}\left(\mathrm{OC}_{4}\right)$. The second stage of the analysis is conducted in a $2 \% \mathrm{O}_{2} / 98 \% \mathrm{He}$ atmosphere and consists of five temperature steps at $550^{\circ} \mathrm{C}\left(\mathrm{EC}_{1}\right)$, $625^{\circ} \mathrm{C}\left(\mathrm{EC}_{2}\right), 700^{\circ} \mathrm{C}\left(\mathrm{EC}_{3}\right), 850^{\circ} \mathrm{C}\left(\mathrm{EC}_{4}\right)$ and $870^{\circ} \mathrm{C}\left(\mathrm{EC}_{5}\right)$. The terms $\mathrm{OC}_{1}-\mathrm{OC}_{4}$ and $\mathrm{EC}_{1}-\mathrm{EC}_{5}$ inside the parentheses refer to the amount of $\mathrm{C}$ released from the filter substrate corresponding to each temperature step. Due to the non-uniform deposition nature of the cascade impactor and the MOUDI samples, laser correction does not work properly to set the OC and EC split point (Huang and Yu, 2008). Instead, positive matrix factorization (PMF2, version 4.2) has been used to apportion the evolved $\mathrm{C}$ peaks $\left(\mathrm{OC}_{1}-\mathrm{OC}_{4}\right.$ and $\left.\mathrm{EC}_{1}-\mathrm{EC}_{5}\right)$ in the thermograms to $\mathrm{OC}$ and EC. The method details are presented in our previous paper ( $\mathrm{Yu}$ and $\mathrm{Yu}, 2009)$. Compared with apparent $\mathrm{EC}$ (AEC, the sum of $\mathrm{EC}_{1}-\mathrm{EC}_{5}$, i.e., the amount of carbon that is released from the filter substrate during the second stage of analysis in $\mathrm{O}_{2} / \mathrm{He}$ atmosphere), the PMF-resolved EC accounts for $77 \%$ of AEC and the PMFresolved OC is $112 \%$ of apparent OC (AOC, the sum of $\mathrm{OC}_{1-}$ $\mathrm{OC}_{4}$ ) in the $\mathrm{GZ}$ urban samples. In the HKUST samples, the PMF-resolved EC is 79\% of AEC and PMF-resolved OC is $115 \%$ of AOC. In the BG samples, the PMF-resolved EC is $81 \%$ of AEC and PMF-resolved OC is $107 \%$ of AOC. It is expected that $\mathrm{AEC}$ would overestimate actual $\mathrm{EC}$ while $\mathrm{AOC}$ would underestimate actual OC since pyrolytically generated EC from charring of OC appears as part of AEC.

Ionic species including sulfate, nitrate, chloride, oxalate, $\mathrm{Na}^{+}, \mathrm{K}^{+}, \mathrm{NH}_{4}^{+}, \mathrm{Ca}^{2+}$, and $\mathrm{Mg}^{2+}$ were determined by ion chromatography (Yang et al., 2005).

\subsection{Light extinction data}

Light extinction data $\left(\sigma_{\text {ext,obs }}\right)$ at the urban sites in GZ were retrieved from visibility records in the SYNOP report of 
(a)

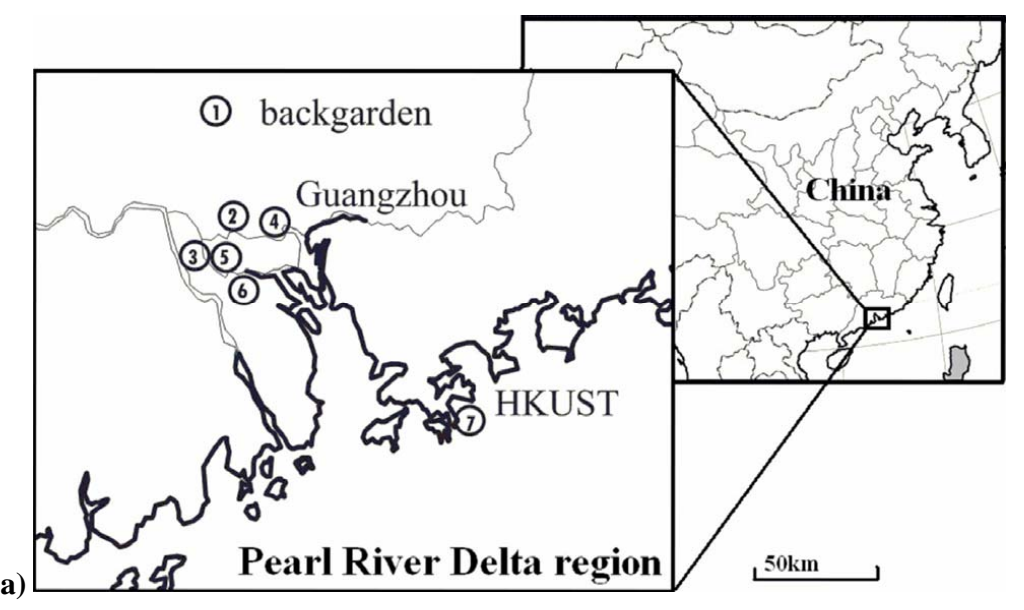

(b)
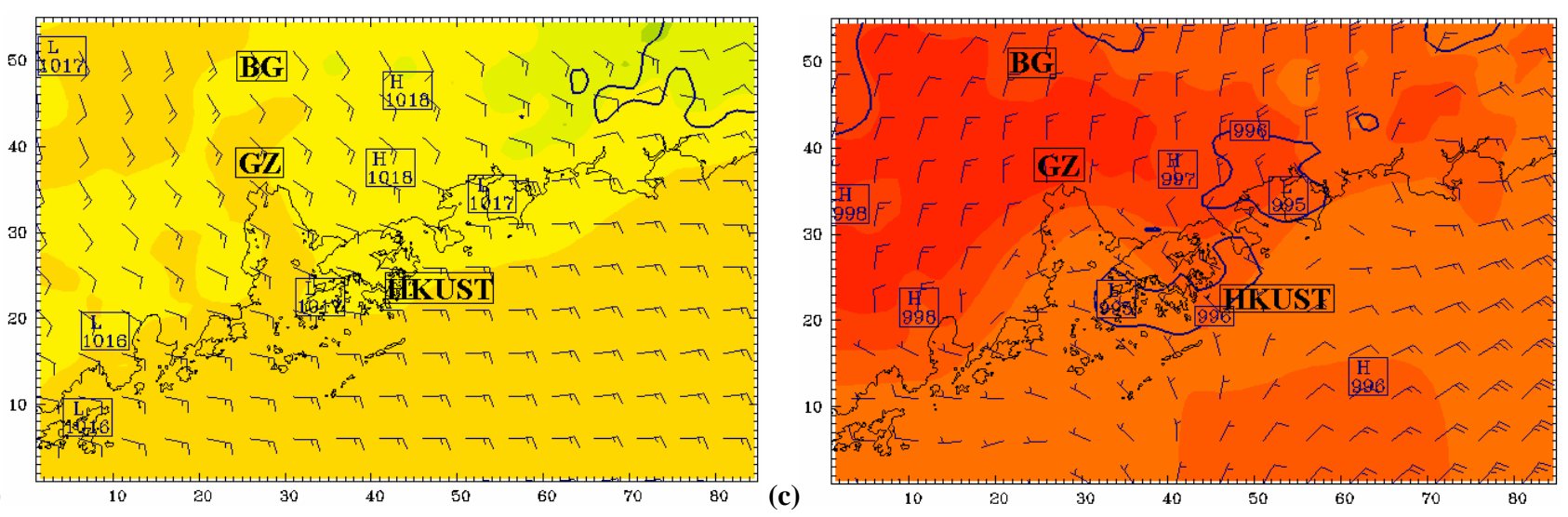

Fig. 1. (a) Locations of five urban sites, one suburban site, and one rural site in the Pearl River Delta region. 1, Rural site at Backgarden; 2, Guangdong Province Meteorological Bureau (GDMB), Yuexiu District; 3, Liwan station; 4, Huangpu station; 5, Haizhu station; 6, Panyu; and 7, HKUST, suburban site in Hong Kong. Sites 2-6 are in the urban area of Guangzhou. (b) Horizontal wind vector map during a HKUST winter sampling day (10 January 2008). (c) Horizontal wind vector map during a BG sampling day (3 July 2006). The wind vector maps were generated by MM5 model based on local surface wind observations in the PRD region (Credit: Environmental Central Facility, HKUST, http://envf.ust.hk/). The color contour indicates the surface temperatures in the region. The surface temperatures ranged from 18 to $22^{\circ} \mathrm{C}$ on the winter sampling days and 30 to $36^{\circ} \mathrm{C}$ on the summer sampling days.

Guangzhou Baiyun airport, located $30 \mathrm{~km}$ to the north of downtown GZ. The $\sigma_{\text {ext,obs values at HKUST were derived }}$ from human visibility observations made at the Hong Kong Observatory (HKO), located $10 \mathrm{~km}$ to the east of HKUST in the same air shed. Comparisons of HKO visibility data and the measurement data by a forward scattering sensor installed at HKUST during the period of 1 January 2008 to 31 March 2009 indicate that the two sets of data were closely correlated (zero-intercept regression results: $r^{2}=0.55$, slope $=1.1$, $n=1307)$ when the HKO visibility was lower than $16 \mathrm{~km}$ $\left(\sigma_{\text {ext,obs }}<244 \mathrm{Mm}^{-1}\right)$, Only on very clean days when the visibility at $\mathrm{HKO}$ was higher than $16 \mathrm{~km}$, the HKO values were higher than HKUST values. For measurement reported in this work, 17 out of 18 sets of samples were collected on days when the HKO visibility was lower than $16 \mathrm{~km}$. Therefore we believe that the HKO data could be used to approximate the visibility at HKUST. We here choose to use the hu- man visibility observations at $\mathrm{HKO}$ on the consideration that the visibility sensor measurements do not reflect light extinction contributions due to absorption of light by aerosols. Visibility data were not available at BG. Instead, aerosol extinction measured by a nephelometer and a photoacoustic spectrometer operated by Max Planck Institute was used (Garland et al., 2008).

\section{Results and discussion}

In the discussion below, the aerosol samples were categorized into five groups, i.e., GZ non-haze day samples, GZ haze day samples, BG summer samples, HKUST summer and winter samples. The determination of a haze day was based on the definition of haze by China Meteorology Administration (CMA). CMA defines haze as visibility degradation with a visual range less than $10 \mathrm{~km}$ caused by aerosols in 
Table 1. Size-segregated aerosol samples collected in selected urban, suburban and rural locations in the pearl river delta region.

\begin{tabular}{|c|c|c|c|c|c|c|}
\hline \multicolumn{2}{|c|}{ Location* } & $\begin{array}{l}\text { period } \\
\text { Dec } 2006\end{array}$ & $\begin{array}{l}\text { \# of sets } \\
3\end{array}$ & $\begin{array}{l}\text { sampler } \\
\text { Andersen Cascade } \\
\text { impactor }\end{array}$ & $\begin{array}{l}\text { Cut points } \\
8 \text { stages, } 0.43-10 \mu \mathrm{m} \\
\text { after filter, }<0.43 \mu \mathrm{m}\end{array}$ & $\begin{array}{l}\text { Visibility data } \\
\text { SYNOP visibility report at } \\
\text { Guangzhou Baiyun Airport }\end{array}$ \\
\hline & site 2 & Apr 2007 & 1 & & & \\
\hline & site $2,3,4,5$ & May 2007 & 4 & & & \\
\hline & site $2,3,4,5$ & Jul 2007 & 4 & & & \\
\hline & site 6 & Oct 2007 & 3 & & & \\
\hline Rural Backgarden & site 1 & Jul 2006 & 7 & MOUDI & 10 stages, $0.056-18 \mu \mathrm{m}$ & $\begin{array}{l}\text { nephelometer and photoa- } \\
\text { coustic spectrometer oper- } \\
\text { ated by Max Planck Insti- } \\
\text { tute }\end{array}$ \\
\hline Suburban HKUST & site 7 & Aug 2007 & 8 & MOUDI & 10stages, $0.056-18 \mu \mathrm{m}$ & $\begin{array}{l}\text { Human observations at } \\
\text { Hong Kong Observatory }\end{array}$ \\
\hline
\end{tabular}

* Locations of sites 1-7 are shown in Fig. 1.

the atmosphere under relatively low relative humidity $(\mathrm{RH})$ conditions (CMA, 2003). All the 29 sets of GZ samples were collected on non-raining days. Eighteen of these samples were collected on non-haze days and eleven collected on haze days according to the CMA definition of haze.

Ambient aerosols are known to consist of multiple size modes. Each size mode is associated with unique growth or formation mechanisms. The size distribution of each mode is described by three parameters, i.e., the mass median aerodynamic diameter (MMAD), the geometric standard deviation $\left(\sigma_{g}\right)$, and the mass concentration $\left(C_{m}\right)$ (Seinfeld and Pandis, 2006). Continuous distributions of the size modes were inverted from the measured mass concentrations in the size bins of the MOUDI or Andersen Impactor samplers using the inversion technique described by Dong et al. (2004). Table 2 lists the average modal characteristics of EC, OC and sulfate in the five sample groups. The average EC size distribution plots are shown in Fig. 2.

\subsection{Modal characteristics of $\mathrm{EC}, \mathrm{OC}$ and sulfate in Guangzhou urban locations}

The total EC concentration was $9.4 \pm 5.1 \mu \mathrm{g} \mathrm{m}^{-3}$ on the haze days and $6.8 \pm 4.1 \mu \mathrm{g} \mathrm{m}^{-3}$ on the non-haze days. The size segregated EC data in GZ were fit with three modes, a condensation mode with an MMAD of 0.36-0.46 $\mu \mathrm{m}$, a droplet mode with an MMAD of $0.8-1.1 \mu \mathrm{m}$, and a coarse mode with an MMAD of 4-7 $\mu \mathrm{m}$. Here, the MMAD ranges refer to the modal peak size ranges in individual samples. Despite the different locations of the five monitoring stations, our results show that the EC size distributions were very similar among the five sites. This similarity may be explained by the fact that GZ is highly urbanized and all the five sites are close to roadside and consequently heavily influenced by vehicular emissions.

The condensation mode was the most prominent mode, accounting for $49 \%$ (non-haze days) and $44 \%$ (haze days) of the total EC mass. A dominant presence of the condensation mode at $\sim 0.40 \mu \mathrm{m}$ was consistent with the EC size distributions measured in a roadway tunnel in this region (Huang et al., 2006) and our earlier measurements using nano-MOUDI (Yu and Yu, 2009). This characteristic of EC size distributions could be explained as a result of high engine loads and low combustion efficiencies in Chinese vehicles. The droplet mode was slightly less abundant, accounting for $30 \%$ (nonhaze days) and 38\% (haze-days). Theoretical analysis by Huang and $\mathrm{Yu}$ (2008) suggests that in-cloud processing can explain the presence of EC in the droplet mode size.

OC and sulfate had the same three modes in the GZ samples. As shown in Table 2, MMADs of OC and sulfate modes were close to those of EC in both sub-groups of the GZ samples. The relative abundances of OC versus EC and sulfate versus EC were dependent on the particle size. The OC/EC ratio in the condensation mode is 0.8 on the non-haze days and 0.9 on the haze days, significantly smaller than those in the droplet mode (1.6 on non-haze days and 2.1 on haze days) (Table 3). These results indicate that $\sim 0.4 \mu \mathrm{m}$ mode EC is fresh soot particles while EC in the $\sim 0.9 \mu$ m mode is aged with extra OC coating. The sulfate/EC ratio is also much higher in the droplet mode, about 2.5 times that in the condensation mode (Table 3), supporting that addition of sulfate through in-cloud processing could cause growth of the EC particles from the condensation mode to the droplet mode.

We also noted a minor difference between haze day samples and non-haze day samples. The condensation mode in the haze day samples peaked at a larger size $(0.41 \pm 0.03 \mu \mathrm{m})$ 

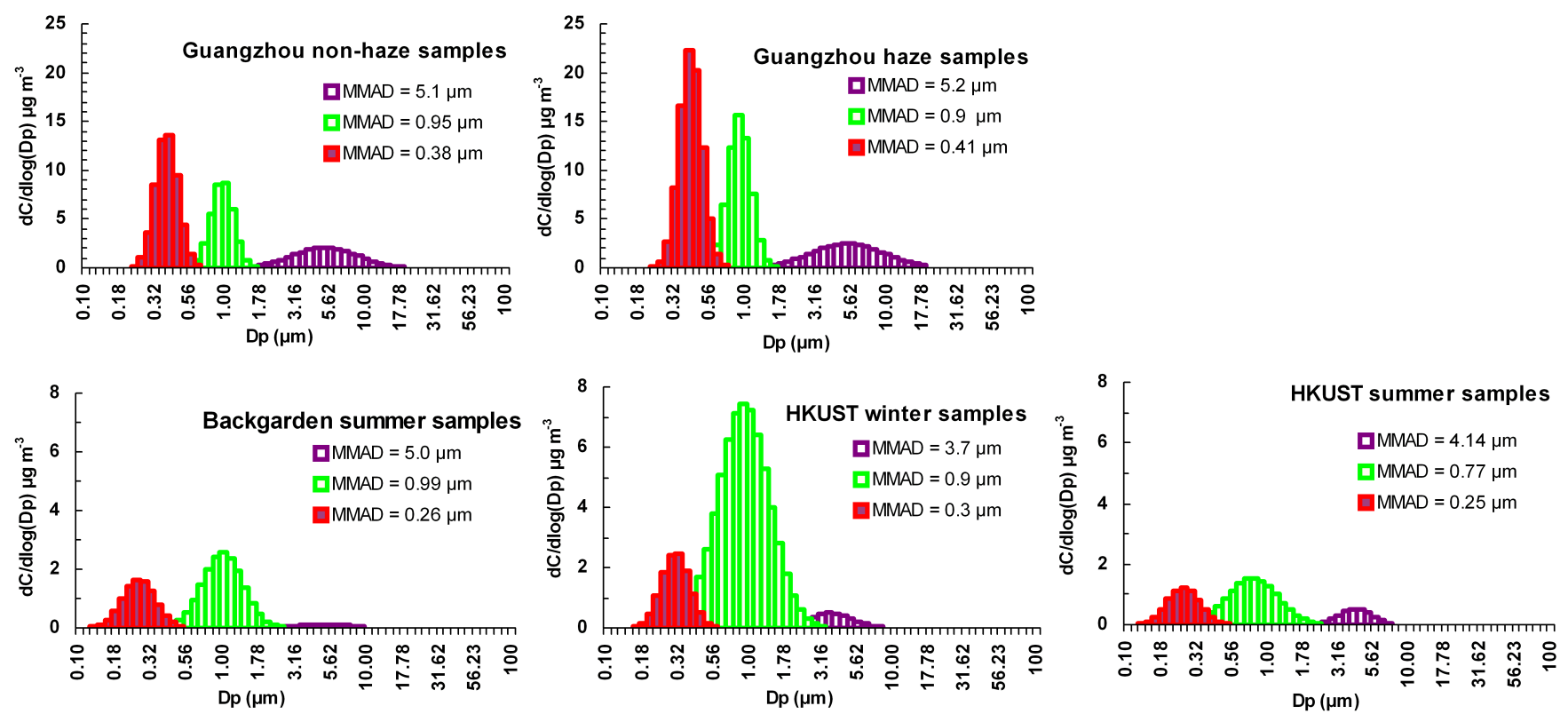

Fig. 2. Mean elemental carbon size distributions in five groups of samples. From top left to bottom right: Guangzhou urban samples on non-haze days, Guangzhou urban samples on haze days, Backgarden summer samples, HKUST winter samples, and HKUST summer samples.

Table 2. MMAD values and modal concentrations of EC, OC, and sulfate in the urban, suburban and rural samples collected in the pearl river delta region.

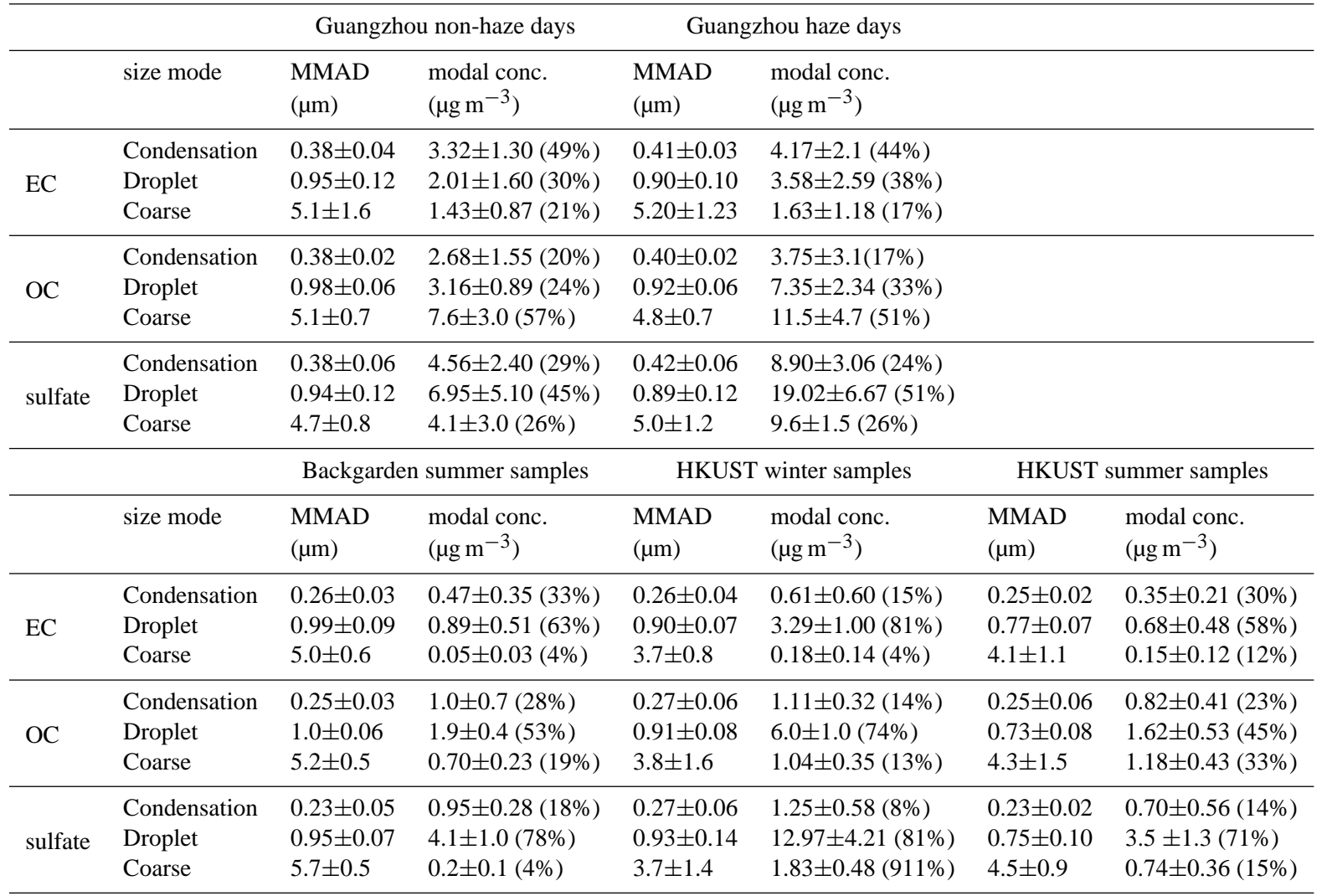


Table 3. The OC/EC and sulfate/EC ratios in three size modes.

\begin{tabular}{lllllll}
\hline & Size mode & $\begin{array}{l}\text { Guangzhou } \\
\text { non-haze days }\end{array}$ & $\begin{array}{l}\text { Guangzhou } \\
\text { haze days }\end{array}$ & $\begin{array}{l}\text { Backgarden } \\
\text { summer samples }\end{array}$ & $\begin{array}{l}\text { HKUST } \\
\text { winter samples }\end{array}$ & $\begin{array}{l}\text { HKUST } \\
\text { summer samples }\end{array}$ \\
\hline \multirow{2}{*}{ OC/EC } & Condensation & 0.80 & 0.90 & 2.10 & 1.80 & 2.34 \\
& Droplet & 1.60 & 2.10 & 2.13 & 1.82 & 2.38 \\
& Coarse & 5.30 & 7.00 & 14.00 & 5.80 & 7.80 \\
\hline \multirow{2}{*}{ sulfate/EC } & Condensation & 1.37 & 2.13 & 2.00 & 2.00 & 2.00 \\
& Droplet & 3.45 & 5.30 & 4.60 & 3.90 & 5.10 \\
& Coarse & 2.80 & 5.80 & 4.00 & 10.10 & 4.90 \\
\hline
\end{tabular}

than that in the non-haze day samples $(0.38 \pm 0.04 \mu \mathrm{m})$. The droplet mode peaked at a smaller size in the haze day samples $(0.90 \pm 0.1 \mu \mathrm{m})$ than in the non-haze day samples $(0.95 \pm 0.12 \mu \mathrm{m})$. The small shift in the modal peak position could be attributed to more semivolatile organics/inorganics available for partitioning onto condensation-mode particles on the haze days, leading to a larger condensation mode. In the meantime, the competition for sulfate by a larger number of cloud-activated aerosol particles led to a smaller droplet mode on the haze days.

\subsection{Modal characteristics of EC, OC, and sulfate at the suburban and rural locations}

The EC concentrations at the rural and suburban locations were significantly lower than those measured at the urban locations, consistent with their respective site characteristics. The total EC concentration was $1.4 \pm 0.8 \mu \mathrm{g} \mathrm{m}^{-3}$ at BG. At HKUST, the average total EC concentration was $4.1 \pm 1.5 \mu \mathrm{g} \mathrm{m}^{-3}$ in the winter samples and $1.2 \pm 0.8 \mu \mathrm{g} \mathrm{m}^{-3}$ in the summer samples.

EC, OC, and sulfate shared similar size distribution characteristics at the two suburban/rural locations, but their size distributions were distinct from those at the urban locations in that the most significant mode was the droplet mode (MMAD: 0.7-1.1 $\mu \mathrm{m}$ ). The droplet-mode EC accounted for $63 \%$ of the total EC mass in the BG samples, $81 \%$ in the HKUST winter samples, and 58\% in the HKUST summer samples. $70-80 \%$ of sulfate and $45-74 \%$ of OC were in the droplet mode at the suburban and rural sites.

The more prominent presence of the droplet mode at the suburban and rural sites was a result of atmospheric aging. $\mathrm{BG}$ is downwind of GZ urban areas during the summer time and HKUST is downwind of the PRD region during the winter time. It took about $2-3 \mathrm{~h}$ for the air mass to move from GZ to the downwind locations (Zhang and Zhang, 2001). During the transport, condensation of semivolatile organics/sulfuric acid/ $\mathrm{NH}_{3}$ results in an organics/sulfate coating on the EC particles (Xiao et al., 2009; Miyazaki et al., 2009). The aged EC particles have a hydrophilic surface and thereby readily act as cloud condensation nuclei (CCN). Upon cloudactivation, oxidation of $\mathrm{SO}_{2}$ in cloud droplets and subsequent water vaporization leads to the growth of the condensationmode EC particles to the droplet mode through addition of sulfate materials. The droplet-mode sulfate/EC ratios are 4.6, 3.9, and 5.1 in the three sample groups, higher than the ratio $(\sim 2)$ in the condensation mode. The enrichment of sulfate in the droplet mode supports the possibility that cloudprocessing of the condensation-mode EC particles occurred.

Under the influence of the prevailing southeast monsoon, HKUST in the summer is often upwind of the PRD region. Consequently, it is influenced less by air pollution produced in the region and less growth in particle size during atmospheric aging is expected due to less abundant condensable materials (e.g., secondary sulfate). This is reflected in the smaller MMAD of the droplet-mode EC $(0.77 \mu \mathrm{m})$ in the HKUST summer samples than those in the BG summer samples and HKUST winter samples (MMAD: 0.9-1.0 $\mu \mathrm{m}$ ).

The condensation mode $(0.22-0.33 \mu \mathrm{m})$ was the second largest mode, accounting for $15-33 \%$ of the total EC mass. It is also noted that the size of the condensation-mode MMAD $(0.22-0.33 \mu \mathrm{m})$ was smaller in the suburban/rural samples than that in the urban samples $(\sim 0.4 \mu \mathrm{m})$. While the OC/EC ratios in the condensation mode (1.8-2.3) are almost equal to those in the droplet mode, they are much higher than the OC/EC ratios (0.8-0.9) in the freshly emitted $0.4 \mu \mathrm{m}$ EC in the urban samples (Table 3). Our earlier measurements at GZ using nano-MOUDI identified two condensation modes, with MMAD values of $\sim 0.15 \mu \mathrm{m}$ and $\sim 0.4 \mu \mathrm{m}$. Atmospheric aging of the $0.15 \mu \mathrm{m}$ EC particles (e.g., vapor condensation) could explain the EC particles in the $0.22-0.33 \mu \mathrm{m}$ condensation mode in the suburban/rural samples. In comparison with the $\sim 0.4 \mu \mathrm{m}$ EC particles, particles in the size range of $0.2-0.3 \mu \mathrm{m}$ are less effectively removed by dry deposition and less likely cloud-activated (Huang et al., 2006; Seinfeld and Pandis, 2006). The combined result of condensation growth and in-cloud processing explains the observation of a condensation-mode EC at an MMAD of $0.22-0.33 \mu \mathrm{m}$, the depletion of the condensation-mode $\mathrm{EC}$ at $0.4 \mu \mathrm{m}$, and the presence of a droplet mode EC at the suburban/rural locations. 


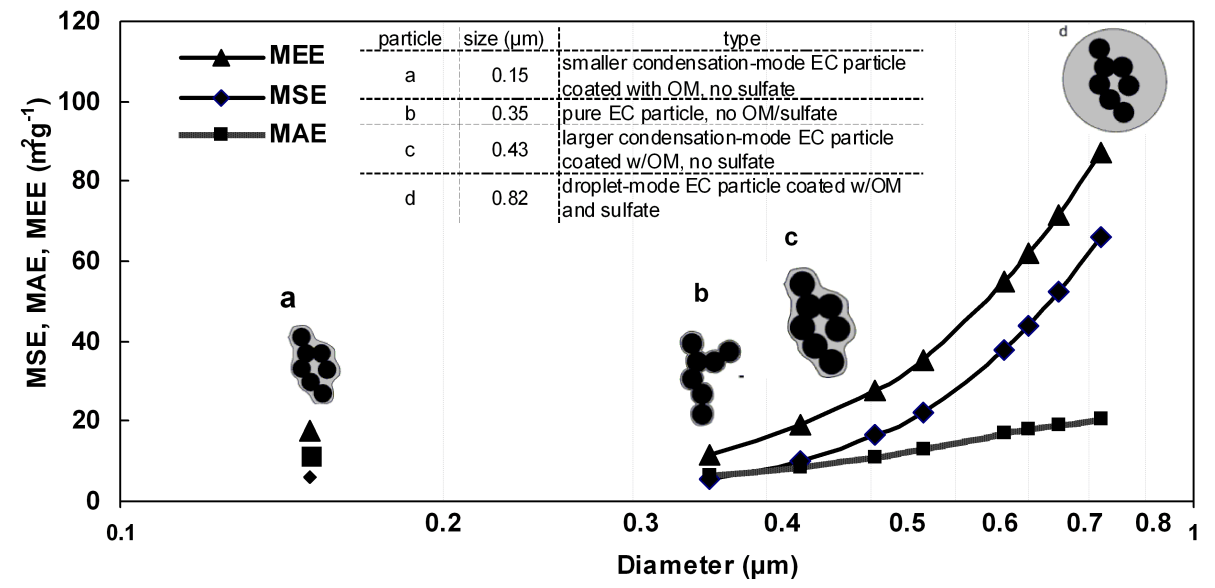

Fig. 3. EC-normalized mass scattering efficiency (MSE), mass absorption efficiency (MAE) and mass extinction efficiency (MEE) of four types of EC-containing particles, taking chemical composition of the HKUST sample collected on 5-6 February 2008 as example.

\subsection{Light extinction due to EC-containing particles}

In this section, we evaluate the contribution of EC-containing particles to aerosol light extinction using Mie theory and the measured size distribution data on EC, OC and inorganic species. We here only consider EC particles in the condensation and the droplet modes, considering that the contribution of coarse-mode EC particles to light extinction is negligible due to their size much larger than the wavelengths of visible light.

Information on chemical composition and number size distribution of EC-containing particles is required in Mie theory calculation (Zhang et al., 1994; Eldering et al., 1994; Lowenthal et al., 1995). The assumptions made in our calculation are described below.

1. In the droplet mode (MMAD: 0.7-1.1 $\mu \mathrm{m}$ ), our analysis in Sects. 3.1 and 3.2 support that EC is internally mixed with ammonium, sulfate, and organic matter $(\mathrm{OM})$. Ammonium and sulfate are the major substances that add to $\mathrm{CCN}$ and cause condensation-mode EC particles to grow to the droplet-mode size. The concentrations of ammonium ion and sulfate ion input to AIM2 (Clegg et al., 1998) are from the measurement data. In our measurements, the molar ratios of $\left[\mathrm{NH}_{4}^{+}\right] /\left[\mathrm{SO}_{4}^{2-}\right]$ range from 1.4 to 2.0, indicating the coexistence of ammonium sulfate and ammonium bisulfate. The amount of water absorbed due to the two forms of sulfate under the respective ambient RH is calculated using AIM2. The observed ambient RH varied from $35 \%$ to $83 \%$ during our sampling periods. The average RH and one standard variation values in the individual sample groups are: $52 \pm 10 \%$ in the GZ non-haze day samples, $64 \pm 5 \%$ in the GZ haze day samples, $77 \pm 4 \%$ in the BG summer samples, $78 \pm 4 \%$ in the HKUST summer samples, and $67 \pm 9 \%$ in the HKUST winter samples. The calculated water content contributes from $10 \pm 4.1 \%$ (GZ samples) to $46 \pm 4.7 \%$ (HKUST summer samples) of the droplet-mode particle mass during the sampling periods. Less is understood about the hygroscopic properties of organic aerosols or inorganic/organic aerosol mixtures. Depending on whether the hydrophobic or the hydrophilic fraction dominates, organics could either enhance or diminish water absorption by inorganics (Saxena et al., 1995). In the original IMPROVE formula (Malm et al., 1994) and the revised IMPROVE formula (Pitchford et al., 2007), water uptake by OM is not considered by setting water growth factor as 1 . We here adopt the same treatment for $\mathrm{OM}$ and do not consider influence of organic materials on water uptake in our calculations.

2. The condensation-mode EC particles are assumed to be internally mixed with OM. Sulfate is assumed to be externally mixed with EC in the condensation mode. We compared the calculated light extinction values for EC-containing particles in the condensation mode under internal versus external mixing scenario with sulfate. In the scenario of internally-mixed EC and sulfate, the calculated light extinction of EC-containing particles in the condensation mode increases 6-9\% at the suburban/rural sites and increases $\sim 30 \%$ at the urban sites. Therefore, the source of the uncertainty for all EC-containing particles (including both the condensation mode and the droplet mode), arising from the mixing state of EC and sulfate in the condensation mode, is less than $9 \%$ at the suburban/rural sites and $30 \%$ at the urban sites.

3. OM or sulfate that is internally mixed with EC has the same lognormal size distributions (i.e., the same MMAD and $\sigma_{g}$ ) as EC. The volume fractions of internally-mixed components are assumed to be uniform for all particles in a given mode. 
4. The refractive index $(n)$ and the density of particles in each mode are determined to be a volume-weighted average of their constituents. Literature values of the refractive index and density adopted are: $1.96-0.66 i$ and $1.5 \mathrm{~g} \mathrm{~cm}^{-3}$ for EC (Hitzenberger et al., 1999; Bond and Bergstorm, 2009), $1.55-0.005 i$ and $1.0 \mathrm{~g} \mathrm{~cm}^{-3}$ for $\mathrm{OM}$ (Mallet et al., 2003), and 1.33-0i and $1.0 \mathrm{~g} \mathrm{~cm}^{-3}$ for water (Hale and Querry, 1973), and 1.53-0i and $1.78 \mathrm{~g} \mathrm{~cm}^{-3}$ for ammonium sulfate (Tang, 1996; Cheng et al., 2006). The refractive index of ammonium bisulfate (1.473-0i) is slightly lower than that of ammonium sulfate $(1.53-0 i)$. We found that the calculated light extinction coefficient is not sensitive to such a small difference in refractive index of the two species. Therefore, the refractive indices of sulfate and bisulfate mixtures are set to be that of ammonium sulfate in all the subsequent calculations. The density of the mixture is also set to be that of ammonium sulfate (Cheng et al., 2006). The number size distribution is calculated from the measured lognormal mass size distribution assuming that all particles are spherical. OM is calculated from OC multiplying by a factor of 1.8 (Hand and Malm, 2006). Finally, with the light wavelength $(\lambda)$ set to $550 \mathrm{~nm}$ (green), Mie scattering efficiency $\left(Q_{\text {sca }}(n\right.$, $\left.D_{p}, \lambda\right)$ ) and Mie absorption efficiency $\left(Q_{\text {abs }}\left(n, D_{p}\right.\right.$, $\lambda)$ ) are integrated over the accumulation particle size range to obtain the light scattering coefficient $\left(\sigma_{\text {sca,calc }}\right)$ and the light absorption coefficient $\left(\sigma_{\text {abs,calc }}\right)$, respectively, in a given mode. The light extinction coefficient, $\sigma_{\text {ext,calc }}$, is the sum of $\sigma_{\text {sca,calc }}$ and $\sigma_{\text {abs,calc }}$.

\subsubsection{Light extinction of EC-containing particles in different size modes}

Three EC-normalized light extinction efficiency parameters, mass absorption efficiency (MAE), mass scattering efficiency (MSE), and mass extinction efficiency (MEE) of these particles are discussed. MAE and MSE of EC-containing particles are defined to be light extinction $\left(\sigma_{\text {ext }}\right)$ by EC particles due to light absorption and scattering, respectively, divided by the EC mass. MEE is the sum of MAE and MSE. The three parameters depend on the particle size and chemical composition of the EC-containing particles. The latter in turn depends on the degree of atmospheric aging and the type of atmospheric aging processes (e.g., vapor condensation versus in-cloud processing).

For the purpose of demonstrating how optical characteristics of EC-containing particles change as the size and chemical composition change over the course of atmospheric aging, the HKUST sample collected on 5-6 February 2008 was used as an example for the calculation of the three light extinction efficiency parameters. Figure 3 shows MAE, MSE, and MEE values of EC-containing particles of different sizes relevant to this example. In this sample, the size distribution was dominated by the droplet mode (MMAD: $0.82 \mu \mathrm{m}$ ) and the modal concentrations for EC, OC, and ammonium sulfate in the droplet mode were 2.1, 3.7, and $15.6 \mu \mathrm{g} \mathrm{m}^{-3}$, respectively. The absorbed water was estimated using AIM2 to be $9.0 \mu \mathrm{g} \mathrm{m}^{-3}$ (Clegg et al., 1998). The droplet mode particles are grown from freshly-emitted EC particles through vapor condensation and cloud processing. It is reasonable to assume that the $0.82 \mu \mathrm{m}$ particle (particle (d) in Fig. 3) is of a spherical core-shell structure with EC being the core and sulfate and OM making up the outside spherical shell. When this particle is stripped of OM, sulfate, and water, the diameter of the EC core left behind is estimated to be $0.35 \mu \mathrm{m}$. We denote this "naked" hypothetical EC particle as particle (b) (Fig. 3). Particle (c) is a $0.43 \mu \mathrm{m}$ condensation-mode particle consisting of the EC core and OM coating, but without sulfate coating, approximating an EC particle in the condensation mode that has been aged in the atmosphere to acquired organic coating but has not participated in cloud-processing.

As shown in Fig. 3, both MAE and MSE increase with the particle diameter in particles containing the same amount of EC mass, but the increase of MSE is much steeper than that of MAE. The MAE and MSE values of the condensationmode EC particles at $0.43 \mu \mathrm{m}$ are calculated to be 8.8 and $10.2 \mathrm{~m}^{2} \mathrm{~g}^{-1}$, respectively. The calculated MAE is in good agreement with the MAE value of $7.7 \mathrm{~m}^{2} \mathrm{~g}^{-1}$ derived for EC in $\mathrm{PM}_{2.5}$ in an urban GZ location from light absorption measurements of dry aerosol using a photoacoustic spectrometer and EC measurements by a thermal/optical method (Andreae et al., 2008). When EC particles of this size grow to the droplet-mode size (e.g., $0.82 \mu \mathrm{m}$, particle (d) in Fig. 3) through sulfate addition during cloud processing, the MAE and MSE values increase to 20.9 and $66.2 \mathrm{~m}^{2} \mathrm{~g}^{-1}$, respectively. In another words, MAE is doubled while MSE increases by more than five-fold when the EC particles grow from the condensation-mode size to the droplet-mode size.

The MAE and MSE of the "naked" EC particle (i.e., particle (b) in Fig. 3) are 6.4 and $5.4 \mathrm{~m}^{2} \mathrm{~g}^{-1}$. Our calculated results are consistent with the estimation by Cheng et al. (2008). They reported that the MAE increases from around 6.0 to $10.0 \mathrm{~m}^{2} \mathrm{~g}^{-1}$ when the EC mixing state changes from an external to an internal mixture.

A smaller condensation-mode EC with an MMAD of $\sim 0.15 \mu \mathrm{m}$ was observed in GZ using nano-MOUDI (Yu and Yu, 2009). EC size distribution measurements made in developed countries typically describe a dominant condensation mode at this size (Miguel et al., 2004; Venkataraman et al., 1994; Maenhaut et al., 2002). We calculated the MAE and MSE of such EC particles at $0.15 \mu \mathrm{m}$ (particle (a) in Fig. 3). The MAE is $11.6 \mathrm{~m}^{2} \mathrm{~g}^{-1}$, higher than the MAE of the $0.43 \mu \mathrm{m}$ particles due to the higher total cross section area associated with the smaller EC particles for the same EC mass. The MSE is $5.9 \mathrm{~m}^{2} \mathrm{~g}^{-1}$, smaller than that of the $0.43 \mu \mathrm{m}$ particles $\left(10.2 \mathrm{~m}^{2} \mathrm{~g}^{-1}\right)$.

The above calculation is based on one HKUST sample. Calculations on other samples from GZ, BG and HKUST show that the "naked" EC particles have a size range of 


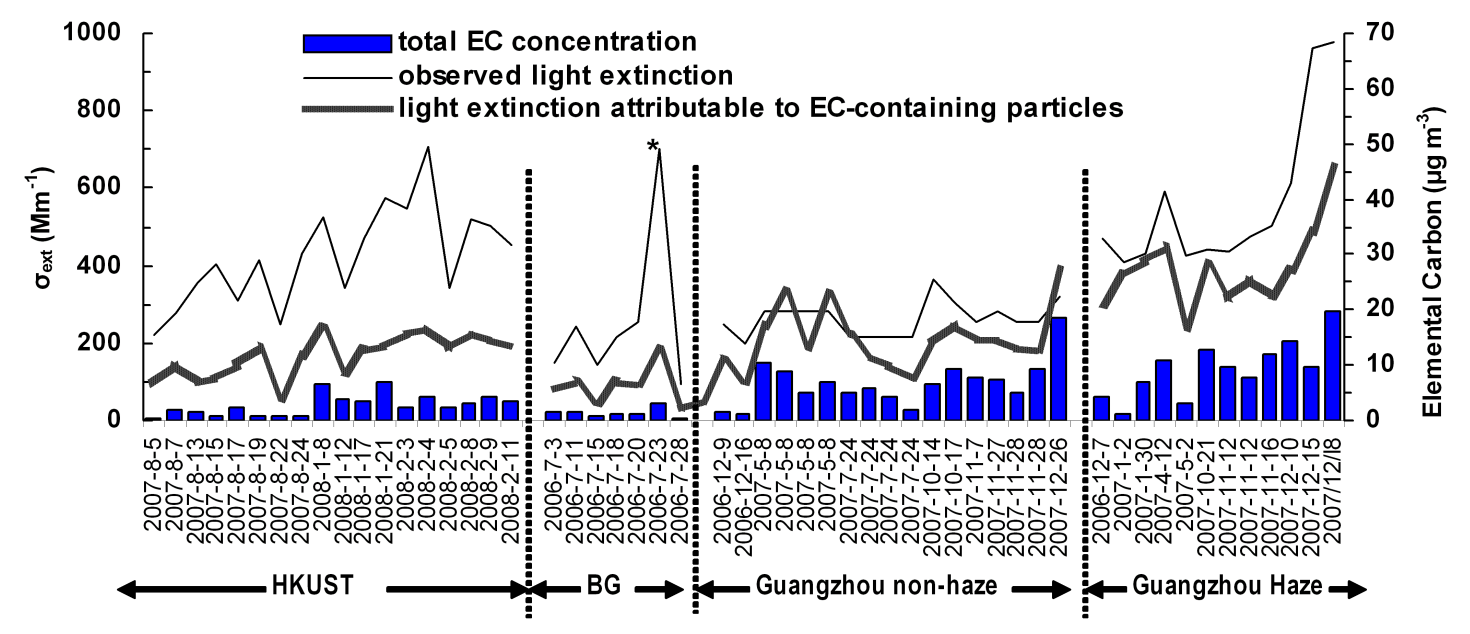

Fig. 4. Calculated and observed light extinction coefficients at the selected urban, suburban and rural locations in the Pearl River Delta region. An episodic biomass burning event occurred nearby the rural sampling site on the sampling day marked with *.

0.3-0.35 $\mu \mathrm{m}$ and MEE of 10.3-14.2 $\mathrm{m}^{2} \mathrm{~g}^{-1}$. The MAE and MSE of the droplet mode particles (particle d) range from 45 to $88 \mathrm{~m}^{2} \mathrm{~g}^{-1}$, apparently dependent on particle size and chemical composition.

The above analysis shows that the light extinction ability of EC particles is greatly enhanced when they grow to the droplet mode as a result of sulfate addition. This in turn suggests that controlling $\mathrm{EC}$ and $\mathrm{SO}_{2}$ emissions is important in improving visibility. We here consider two simplified control scenarios to probe the relative effectiveness of controlling $\mathrm{SO}_{2}$ and $\mathrm{EC}$ emissions on reducing the light extinction of droplet-mode EC particles. In the base scenario, the modal concentrations for EC, OC and ammonium sulfate are set to be $2.1,3.7$, and $15.6 \mu \mathrm{g} \mathrm{m}^{-3}$, respectively. In the first control scenario, the EC concentration is maintained as in the base case while sulfate is reduced by half; $\sigma_{\text {ext }}$ decreases by $26 \%$ with $23 \%$ due to scattering reduction and $3 \%$ due to absorption reduction. In the second control scenario, sulfate is maintained as in the base case while EC is reduced by half; $\sigma_{\text {ext }}$ decreases by $32 \%$ with $24 \%$ from scattering and $8 \%$ from absorption. These simple calculations demonstrate that control of both EC and $\mathrm{SO}_{2}$ could have significant benefits in reducing light attenuation caused by droplet-mode EC particles.

\subsubsection{Contribution of EC-containing particles to observed light extinction}

The observed total light extinction $\left(\sigma_{\text {ext,obs }}\right.$ in $\mathrm{Mm}_{\text {) }}^{-1}$ is calculated using the Koschmieder relationship, $\sigma_{\text {ext,obs }}=$ $3.912 / R(V)$, where $R(V)$ is the average visual range during the sampling period of each sample. Light extinction due to EC-containing particles is calculated to be the sum of the $\sigma_{\text {ext }}$ values of the droplet-mode and the condensation-mode EC particles. The calculated values $\left(\sigma_{\text {ext,calc }}\right)$ are compared with the observed total light extinction in Fig. 4. The EC concentrations are also shown in Fig. 4.

At the GZ urban locations, $\sigma_{\text {ext,cal }}$ by EC-containing particles closely tracked $\sigma_{\text {ext,obs }}$ (Fig. 4) and accounted for a major fraction of the observed light extinction. EC-containing particles explained $211 \pm 77.1 \mathrm{Mm}^{-1}\left(80 \pm 23 \%\right.$ of $\left.\sigma_{\text {ext,obs }}\right)$ on the non-haze days and $392 \pm 107 \mathrm{Mm}^{-1}(72 \pm 15 \%$ of $\left.\sigma_{\text {ext,obs}}\right)$ on the haze days.

EC-containing particles at the suburban and rural locations accounted for a much reduced fraction of $\sigma_{\text {ext,obs. The light }}$ extinction by EC particles at HKUST was modeled to be $126 \pm 42 \mathrm{Mm}^{-1}$ in the summer samples and $201 \pm 35 \mathrm{Mm}^{-1}$ in the winter samples, accounting for $37 \pm 13 \%$ and $48 \pm 7 \%$ of the observed light extinction. In the BG summer samples, the EC particles attributed $90 \pm 49 \mathrm{Mm}^{-1}$, accounting for $38 \pm 9 \%$ of the $\sigma_{\text {ext,obs. }}$.

There was a large difference in the relative contributions of condensation-mode and droplet-mode EC particles to light extinction between the urban locations and the suburban/rural locations. Figure 5 compares the relative contributions to light extinction by EC in the two size modes. At the suburban and rural sites, the droplet-mode EC particles dominated the contribution to light extinction by EC, with the droplet mode accounting for $87 \pm 7 \%$ of light extinction attributable to EC-containing particles at HKUST and $77 \pm 8 \%$ at BG. In comparison, the droplet mode contributed only $40 \pm 12 \%$ to $\sigma_{\text {ext,calc }}$ by EC in GZ. This difference between urban and suburban/rural locations was linked to the relative abundance of EC particles in the two modes. The condensation-mode EC was more abundant in the urban atmosphere due to fresh vehicle emissions. When the air mass moved from the urban source regions to the suburban and rural locations, the condensation-mode EC particles were diluted and some of them grew to the droplet mode. Sulfate and water coating formed in the atmospheric aging 


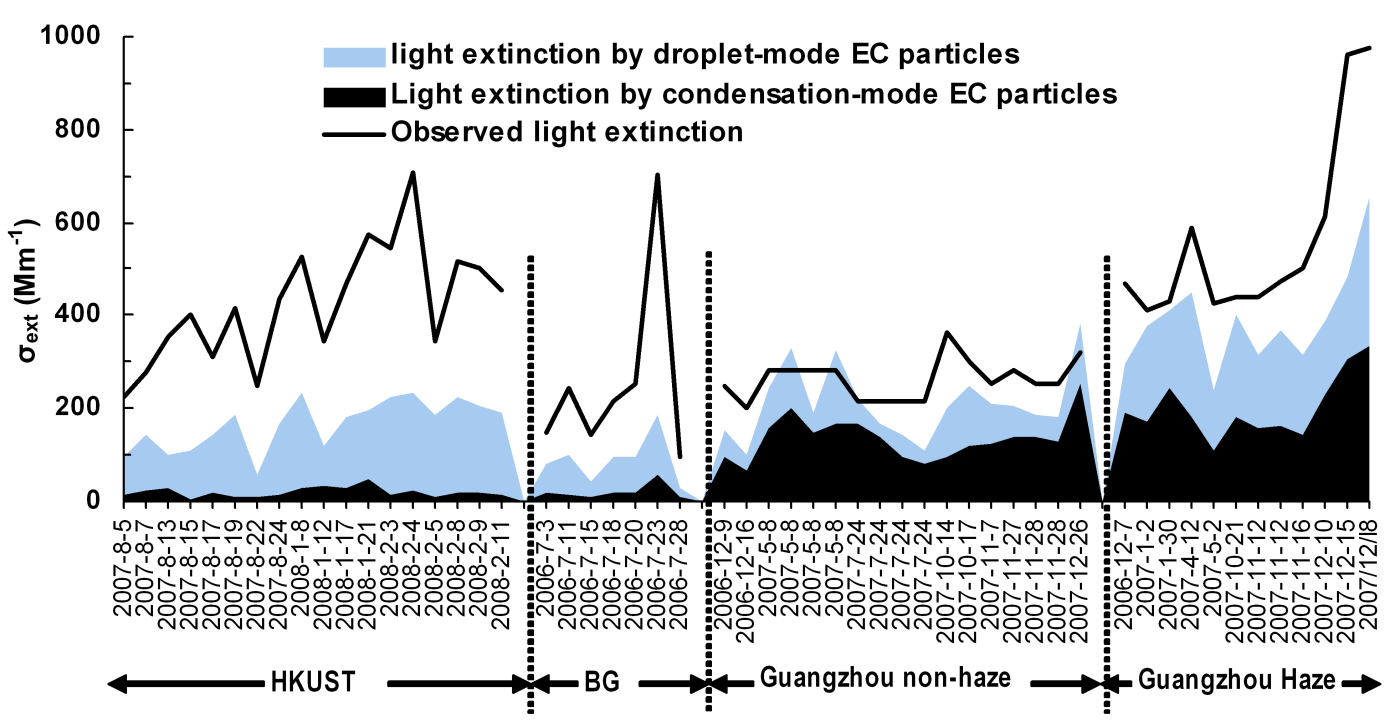

Fig. 5. Contributions of droplet-mode and condensation-mode EC-containing particles to the observed light extinction at a few selected urban, suburban and rural locations in the Pearl River Delta region.

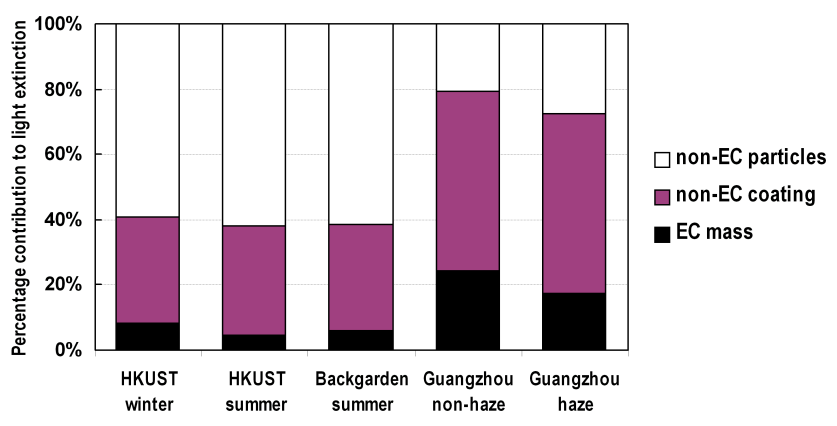

Fig. 6. Contributions of EC and non-EC coating in EC-containing particles to the observed light extinction coefficients in a few urban, suburban and rural locations in the Pearl River Delta region. The fraction of others was calculated to be the difference between the observed light extinction and the light extinction of EC-containing particles.

processes significantly increased the light scattering of the EC-containing particles in the droplet-mode size.

\subsubsection{Contributions of EC and non-EC materials in EC- containing particles to observed light extinction}

The mass of EC-containing particles consists of EC and nonEC materials (i.e., OM, ammonium sulfate, or water). We next apportion $\sigma_{\text {ext,cal }}$ to EC and non-EC materials in the EC-containing particles. Because EC and non-EC materials were internally mixed, it is not appropriate to estimate the light extinction of each species separately by assuming they were externally mixed. Instead, we stripped non-EC materials from EC-containing particles to obtain new size distributions of "naked" EC particles (i.e., from particles (d) and (c) to particle (b) in Fig. 3). The light extinction of "naked" EC particles was estimated based on the new size distribution. Then, the light extinction by non-EC materials in the EC-containing particles was calculated to be the difference in light extinction between the internally mixed and the "naked" EC particles.

Contributions to the light extinction from EC and nonEC materials at different sites are compared in Fig. 6. In the GZ urban locations, EC contributed $24 \pm 12 \%$ (non-haze days) and $17 \pm 8 \%$ (haze days) of the observed light extinction, while the non-EC coating contributed $55 \pm 15 \%$ (nonhaze days) and $55 \pm 16 \%$ (haze days). At the suburban and rural locations, the contributions from EC were much smaller, ranging from $4 \pm 2 \%$ in the HKUST summer samples, $6 \pm 3 \%$ in the BG summer samples to $10 \pm 3 \%$ in the HKUST winter samples. The non-EC coating contributed 32-38\% of the observed light extinction at HKUST and BG. We note that the non-EC coating materials were dominated by sulfate. Consequently, our results are consistent with light extinction source apportioning studies that generally report sulfate to be a major contributor to visibility degradation at urban and rural sites around the world (e.g., Groblicki et al., 1981; Wang, 2003; Kim et al., 2008).

While the EC-containing particles could explain $76 \pm 20 \%$ of the light extinction observed in GZ, the EC-containing particles played a smaller role in the light extinction budget at BG and HKUST. The EC particles accounted for $41 \pm 6 \%$ of the light extinction in the winter HKUST samples, $38 \pm 10 \%$ in the summer HKUST, and $38 \pm 9 \%$ in the summer BG samples. The lower percentage contribution to light extinction by EC particles was a result of that the non-EC particles (nitrate, sea salt, etc.) likely made up a higher percentage of the particle population at the suburban and rural sites than the urban 
site. More of the sulfate mass existed either as externally mixed sulfate particles or internally mixed with other non-EC particles, for example, sea salt particles and biomass burning particles. At the HKUST site, sea salt aerosols are abundant in the summer under the prevailing southerly wind. Marine aerosols could play a role in light extinction at HKUST. At the BG site, local biomass burning emissions were a significant aerosol source in addition to transported urban emissions from upwind urban areas. During the measurement periods, the average $\mathrm{K}^{+}$concentration was $0.25 \mu \mathrm{g} \mathrm{m}^{-3}$ at BG versus $0.08 \mu \mathrm{g} \mathrm{m}^{-3}$ in $\mathrm{GZ}$, indicating that BG was more influenced by biomass burning emissions. One episodic biomass burning event nearby occurred during 23-25 July, leading to a spike $\left(703 \mathrm{Mm}^{-1}\right)$ in the average $\sigma_{\text {ext,obs }}$ at BG (Garland et al., 2008). In the sample we collected during this period, ECcontaining particles contributed only $26 \%$ to $\sigma_{\text {ext,obs }}$. Certain known soluble inorganics (e.g., $\mathrm{KCl}$ ) in biomass burning aerosols and their associated water could account for a significant fraction of light extinction.

\section{Summary}

Measurements made in this study indicate that EC size distributions were different at urban and suburban/rural locations in the Pearl River Delta region in South China. At GZ urban locations, the condensation mode with an MMAD in $0.36-0.43 \mu \mathrm{m}$ was the most abundant mode, accounting for $44-49 \%$ of the total EC mass. The droplet mode with an MMAD of 0.8-1.1 $\mu \mathrm{m}$ was the next abundant mode, accounting for 30-38\% of the total EC mass. At the suburban and rural sites, the droplet mode was the dominant mode, contributing $58-81 \%$ to the total EC mass, followed by the condensation mode that contributed $15-33 \%$. Mie theory and the size-segregated chemical composition data were used to calculate the contribution to light extinction by EC-containing particles. Our calculations show that EC-containing particles could explain $76 \pm 20 \%$ of the observed light extinction in GZ and non-EC materials on the EC particles provide a significant fraction of the scattering aerosol mass. Control of both $\mathrm{EC}$ and $\mathrm{SO}_{2}$ (precursor to sulfate, the dominant coating material on EC-particles) could have significant benefits in improving visibility. At the suburban and rural locations, the contribution to light extinction by EC-containing particles was reduced to about $40 \%$. Further measurements and modeling work are required to reconstruct the contribution budget of light extinction in the PRD region, especially in suburban and rural sites.

Acknowledgements. This work was partially supported by the Research Grants Council of Hong Kong, China (621405), HKUST Fok Ying Tung Graduate School, Natural Science Foundation of China (Grant U0733004 and 40775011). We thank Peking University for organizing the PRIDE-PRD 2006 campaign, which was mainly sponsored by China National Basic Research and Development Program-2002CB410801 and 2002CB211605.
Edited by: A. Hofzumahaus

\section{References}

Andreae, M. O., Schmid, O., Yang, H., Chand, D., Yu, J. Z., Zeng, L. M., and Zhang, Y. H.: Optical properties and chemical composition of the atmospheric aerosol in urban Guangzhou, China, Atmos. Environ., 42, 6335-6350, 2008.

Bergin, M. H., Cass, G. R., Xu, J., Fang, C., Zeng, L. M., Yu, T., Salmon, L. G., Kiang, C. S., Tang, X. Y., Zhang, Y. H., and Chameides, W. L.: Aerosol radiative, physical, and chemical properties in Beijing during June 1999, J. Geophys. Res.-Atmos., 106(D16), 17969-17980, 2001.

Birch, M. E. and Cary, R. A.: Elemental carbon-based method for monitoring occupational exposures to particulate diesel exhaust, Aerosol Sci. Technol., 25, 221-241, 1996.

Bohren, C. F. and Huffman D. R.: Absorption and scattering of light by small particles, John Wiley, Hoboken, N. J., 1983.

Bond, T. C. and Bergstrom, R. W.: Light absorption by carbonaceous particles: An investigative review, Aerosol Sci. Technol., 40, 27-67, 2006.

Cao, J. J., Lee, S. C., Ho, K. F., Zhang, X. Y., Zou, S. C., Fung, K., Chow, J. C., and Watson, J. G.: Characteristics of carbonaceous aerosol in Pearl River Delta Region, China during 2001 winter period, Atmos. Environ., 37, 1451-1460, 2003.

Cao, J. J., Lee, S. C., Ho, K. F., Zou, S. C., Fung, K., Li, Y., Watson, J. G., and Chow, J. C.: Spatial and seasonal variations of atmospheric organic carbon and elemental carbon in Pearl River Delta Region, China, Atmos. Environ., 38, 4447-4456, 2004.

Chang, W. L. and Koo, E.: A study of visibility trends in Hong Kong (1968-1982), Atmos. Environ., 20, 1847-1858, 1986.

Cheng, Y. F., Eichler, H., Wiedensohler, A., Heintzenberg, J., Zhang, Y. H., Hu, M., Herrmann, H., Zeng, L. M., Liu, S., Gnauk, T., Bruggemann, E., and He, L. Y.: Mixing state of elemental carbon and non-light-absorbing aerosol components derived from in situ particle optical properties at Xinken in Pearl River Delta of China, J. Geophys. Res., 111, D20204, doi:10.1029/2005JD006929, 2006.

Cheng, Y. F., Wiedensohler, A., Eichler, H., Su, H., Gnauk, T., Bruggemann, E., Herrmann, H., Heintzenberg, J., Slanina, J., Tuch, T., Hu, M., and Zhang, Y.H.: Aerosol optical properties and related chemical apportionment at Xinken in Pearl River Delta of China, Atmos. Environ., 42, 6351-6372, 2008.

China Meteorology Administration: Specifications for Surface Meteorological Observation, China Meteorological Press, 2003.

Chow, J. C., Watson, J. G., Louie, P. K. K., Chen, L.-W. A., and Sin, D.: Comparison of $\mathrm{PM}_{2.5}$ carbon measurement methods in Hong Kong, China, Environ. Pollut., 137, 334-344, 2005.

Clegg, S. L., Brimblecombe, P., and Wexler, A. S.: A thermodynamic model of the system $\mathrm{H}^{+}-\mathrm{NH}_{4}^{+}-\mathrm{SO}_{4}^{2-}-\mathrm{NO}_{3}^{-}-\mathrm{H}_{2} \mathrm{O}$ at tropospheric temperatures, J. Phys. Chem. A, 102, 2137-2154, 1998.

Duan, J., Tan, J., Cheng, D., Bi, X., Deng, W., Sheng, G., Fu, J., and Wong, M.H.: Sources and characteristics of carbonaceous aerosol in two largest cities in Pearl River Delta Region, China, Atmos. Environ., 41, 2895-2903, 2007.

Dong, Y., Hays, M. D., Smith, N. D., and Kinsey, J. S.: Inverting cascade impactor data for size-resolved characterization of fine 
particulate source emissions, J. Aerosol. Sci., 35, 1497-1512, 2004.

Eldering, A., Cass, G. R., and Moon, K. C.: Monitoring network using continuous particle size distribution monitors: Connecting pollutant properties to visibility via Mie scattering calculations, Atmos. Environ., 28(16), 2733-2749, 1994.

Fung, J. C. H., Lau, A. K. H., Lam, J. S. L., and Yuan, Z.: Observational and modeling analysis of a severe air pollution episode in western Hong Kong, J. Geophys. Res., 110, D09105, doi:10.1029/2004JD005105, 2005.

Garland, R. M., Yang, H., Schmid, O., Rose, D., Nowak, A., Achtert, P., Wiedensohler, A., Takegawa, N., Kita, K., Miyazaki, Y., Kondo, Y., Hu, M., Shao, M., Zeng, L. M., Zhang, Y. H., Andreae, M. O., and Pöschl, U.: Aerosol optical properties in a rural environment near the mega-city Guangzhou, China: implications for regional air pollution, radiative forcing and remote sensing, Atmos. Chem. Phys., 8, 5161-5186, doi:10.5194/acp-85161-2008, 2008.

Gnauk, T., Müller, K., van Pinxteren, D., He, L. Y., Niu, Y., Hu, M., and Herrmann, H.: Size-segregated particulate chemical composition in Xinken, Pearl River Delta, China: OC/EC and organic compounds, Atmos. Environ., 42, 6296-6309, 2008.

Groblicki, P. J., Wolff, G. T., and Countess, R. J.: Visibilityreducing species in the Denver "brown cloud" - I. Relationship between extinction and chemical composition, Atmos. Environ., 15, 2473-2484, 1981.

Guangzhou Transport Planning Research Institute: Annual report on transport development of Guangzhou, 2006. http://www. gztpri.com/journal-viewer.asp?id=3, last accessed on August 21, 2009.

Hagler, G. S. W., Bergin, M. H., Salmon, L. G., Yu, J. Z., Wan, E. C. H., Zheng, M., Zeng, L. M., Kiang, C. S., Zhang, Y. H., Lau, A. K. H., and Schauer, J. J.: Source areas and chemical composition of fine particulate matter in the Pearl River Delta region of China, Atmos. Environ., 40, 3802-3815, 2006.

Hale, G. M. and Querry, M. R.: Optical Constants of Water in the 200-nm to 200- $\mu \mathrm{m}$ Wavelength Region, Appl. Optics, 12(3), 555-563, doi:10.1364/AO.12.000555, 1973.

Hasan, H. and Dzubay, T. G.: Apportioning light extinction coefficients to chemical species in atmospheric aerosol, Atmos. Environ., 17(8), 1573-1581, 1983.

Hitzenberger, R., Jennings, S. G., Larson, S. M., Dillner, A., Cachier, H., Galambos, Z., Rouc, A., and Spain, T. G.: Intercomparison of measurement methods for black carbon aerosols, Atmos. Environ., 33, 2823-2833, 1999.

Ho, K. F., Lee, S. C., Cao, J. J., Li, Y. S., Chow, J. C., Watson, J. G., and Fung, K.: Variability of organic and elemental carbon, water soluble organic carbon, and isotopes in Hong Kong, Atmos. Chem. Phys., 6, 4569-4576, doi:10.5194/acp-6-4569-2006, 2006.

Ho, K. F., Lee, S. C., Yu, J. C., Zou, S. C., and Fung, K.: Carbonaceous characteristics of atmospheric particulate matter in Hong Kong, Sci. Total Environ., 300, 59-67, 2002.

Horvath, H.: Atmospheric light absorption - a review, Atmos. Environ., 27A, 293-317, 1993.

Horvath H.: Size segregated light absorption coefficient of the atmospheric aerosol, Atmos. Environ., 29(8), 875-883, 1995.

Huang, X.-F. and Yu, J. Z.: Size distributions of elemental carbon in the atmosphere of a coastal urban area in South China: char- acteristics, evolution processes, and implications for the mixing state, Atmos. Chem. Phys., 8, 5843-5853, doi:10.5194/acp-85843-2008, 2008.

Huang, X. F., Yu, J. Z., He, L.Y., and Hu, M.: Size distribution characteristics of elemental carbon emitted from Chinese vehicles: Results of a tunnel study and atmospheric implications, Environ. Sci. Technol., 40, 5355-5360, 2006.

Jacobson, M. Z.: Strong radiative heating due to the mixing state of black carbon in atmospheric aerosols, Nature, 409, 695-697, 2001.

Kim, K. W., Kim, Y. J., and Bang, S. Y.: Summer time haze characteristics of the urban atmosphere of Gwangju and the rural atmosphere of Anmyon, Korea, Environ. Monit. Assess., 141, 89199, 2008.

Lai, L. Y. and Sequeira, R.: Visibility degradation across Hong Kong: its components and their relative contributions, Atmos. Environ., 35(34), 5861-5872, 2001.

Lowenthal, D. H., Rogers, C. F., Saxena, P., Watson, J. G., and Chow, J. C.: Sensitivity of estimated light extinction coefficients to model assumptions and measurement errors, Atmos. Environ., 29(7), 751-766, 1995.

Maenhaut, W., Cafmeyer, J., Dubtsov, S., and Chi, X. G.: Detailed mass size distributions of elements and species, and aerosol chemical mass closure during fall 1999 at Gent, Belgium, Nucl. Instrum. Methods Phys. Res. Sect. B-Beam Interact. Mater. Atoms., 189, 238-242, 2002.

Mallet, M., Roger, J. C., Despiaua, S., Dubovik, C., and Putaud, J. P.: Microphysical and optical properties of aerosol particles in urban zone during ESCOMPTE, Atmos. Res., 69, 73-97, 2003.

Malm, W. C., Gebhart, K. A., Molenar, J., Cahill, T., Eldred, R., and Huffman, D.: Examining the Relationship between Atmospheric Aerosols and Light Extinction at Mount Rainier and North Cascades National Parks, Atmos. Environ., 28(2), 347-360, 1994.

Miguel, A. H., Eiguren-Fernandez, A., Jaques, P. A., Froines, J. R., Grant, B. L., Mayo, P. R., and Sioutas, C.: Seasonal variation of the particle size distribution of polycyclic aromatic hydrocarbons and of major aerosol species in Claremont, California, Atmos. Environ., 38, 3241-3251, 2004.

Miyazaki, Y., Kondo, Y., Shiraiwa, M., Takegawa, N., Miyakawa, T., Han, S., Kita, K., Hu, M., Deng, Z. Q., Zhao, Y., Sugimoto, N., Blake, D. R., and Weber, R. J.: Chemical characterization of water-soluble organic carbon aerosols at a rural site in the Pearl River Delta, China, in the summer of 2006, J. Geophys. Res., 114, D14208, doi:10.1029/2009JD011736, 2009.

Pitchford, M., Malm, W. C., Schichtel, B., Kumar, N., Lowenthal, D., and Hand, J.: Revised algorithm for estimating light extinction from IMPROVE particle speciation data, J.Air and Waste Manage. Assoc., 57, 1326-1336, doi:10.3155/10473289.57.11.1326, 2007.

Saxena, P., Hildemann, L. M., McMurry, P. H., and Seinfeld, J. H.: Organics alter hygroscopic behavior of atmospheric particles, J. Geophys. Res., 100D, 18755-18770, 1995.

Seinfeld, J. H. and Pandis, S. N.: Atmospheric Chemistry and Physics - From Air Pollution to Climate Change (2nd Edition), John Wiley and Sons, p. 362, p. 905, 2006.

Sloane, C. S., Watson, J., Chow, J., Pritchett, L., and Richards, L.W.: Size-segregated fine particle measurements by chemical species and their impact on visibility impairment in Denver, Atmos. Environ. - Part A General Topics, 25(5-6), 1013-1024, 
1991.

Tang, A. N.: Chemical and size effects of hygroscopic aerosols on light scattering coefficients, J. Geophys. Res., 101, 1924519250, 1996.

Van de Hulst, H. C.: Light Scattering by Small Particles, New York, Dover, 470pp., 1981.

Vanderlei, M. J., Artaxo, P., Liousse, C., Reid, J. S., Hobbs, P. V., and Kaufman, Y. J.: Effects of black carbon content, particle size, and mixing on light absorption by aerosols from biomass burning in Brazil, J. Geophys. Res., 103(D4), 32041-32050, 1998.

Venkataraman, C. and Friedlander, S. K.: Size distributions of polycyclic aromatic hydrocarbons and elemental carbon: 2. Ambient measurements and effects of atmospheric processes, Environ. Sci. Technol., 28, 563-572, 1994.

Wang, T.: Study of Visibility Reduction and its Causes in Hong Kong, final report to Air Services Group of The Environmental Protection Department of HKSAR, March 2003.

Wu, D., Bi, X. Y., Deng, X. J., Li, F., Tan, H.B., Liao, G. L., and Huang, J.: Effect of atmospheric haze on the deterioration of visibility over the Pearl River Delta, Acta Meteor. Sinica, 21, 215-223, 2007.

Xiao, R., Takegawa, N., Kondo, Y., Miyazaki, Y., Miyakawa, T., Hua, M., Shao, M., Zeng, L. M., Hofzumahaus, A., Holland, F., Lu, K., Sugimoto, N., Zhao, Y., and Zhang, Y. H.: Formation of submicron sulfate and organic aerosols in the outflow from the urban region of the Pearl River Delta in China, Atmos. Environ., 43, 3754-3763, doi:10.1016/j.atmosenv.2009.04.028, 2009.
Yang, H., Yu, J. Z., Ho, S. S. H., Xu, J. H., Wu, W. S., Wan, C. H., Wang, X. D., Wang, X. R., and Wang, L. S.: The chemical composition of inorganic and carbonaceous materials in $\mathrm{PM}_{2.5}$ in Nanjing, China, Atmos. Environ., 39(20), 3735-3749, 2005.

Yu, J. Z., Tung, J. W. T., Wu, A. W. M., Lau, A. K. H., Louie, P. K. K., and Fung, J. C. H.: Abundance and seasonal characteristics of elemental and organic carbon in Hong Kong $\mathrm{PM}_{10}$, Atmos. Environ., 38, 1511-1521, 2004.

Yu, H. and Yu, J. Z.: Modal Characteristics of Elemental and Organic Carbon in an Urban Location in Guangzhou, China, Aerosol Sci. Technol., 43, 1108-1118, 2009.

Zhang, X., Turpin, B. J., McMurry, P. H., Hering, S. V., and Stolzenburg, M. R.: Mie theory evaluation of species contributions to 1990 wintertime visibility reduction in the Grand Canyon, J. Air and Waste Manage. Assoc., 44(2), 153-162, 1994.

Zhang, Q. Y. and Zhang, Y. H.: Research on atmospheric boundary layer and pollution in Chinese cities, Research Progress on Urban Environmental Meteorology in China and Overseas, issue 2, 2001. Available at http://library.cma.gov.cn/publications/ 973environment/cshj0102.htm. 